\title{
Cytotoxic and antioxidant properties of Borneo Garcinia species (Clusiaceae)
}

\begin{abstract}
There are several local Malaysian Garcinia species which have ethnobotanical uses but so far very few studies have been carried out to link these folkloric uses with the phytochemistry of these plant species. It would be interesting therefore, to develop phytochemical data of two such Sarawakian species which are Garcinia eugenifolia and Garcinia nitida which have not been reported before. The methanol extract from the G. eugenifolia leaves exhibited moderate antioxidant activity with EC50 values of 66 and 51 respectively, when compared to ascorbic acid with EC50 values of $15.32 \mathrm{\varepsilon g} / \mathrm{mL}$. This crude also showed weak cytotoxic activity to HeLa with IC50 values of 71 and $40 \mathrm{gg} / \mathrm{mL}$ respectively. However, the leaves extracts of G. nitida showed good cytotoxic activity with IC50 values of 4 and $7 \mathrm{gg} / \mathrm{mL}$ respectively towards both cell lines.
\end{abstract}

Keyword: Garcinia eugenifolia; Garcinia nitida; Cytotoxic; Antioxidant 